\title{
Targeting Anaplastic Lymphoma Kinase (ALK) in Rhabdomyosarcoma (RMS) with the Second-Generation ALK Inhibitor Ceritinib
}

\author{
Anke E. M. van $\operatorname{Erp}^{1}{ }^{1}$ ( ) Melissa H. S. Hillebrandt-Roeffen ${ }^{1} \cdot$ Laurens van Houdt $^{1}$ • \\ Emmy D. G. Fleuren ${ }^{2}$ - Winette T. A. van der Graaf ${ }^{1,3}$ • \\ Yvonne M. H. Versleijen-Jonkers ${ }^{1}$
}

Published online: 24 October 2017

(C) The Author(s) 2017. This article is an open access publication

\begin{abstract}
Background The receptor tyrosine kinase (RTK) anaplastic lymphoma kinase (ALK) has been implicated in the tumorigenesis of rhabdomyosarcoma (RMS). However, the exact role of ALK in RMS is debatable and remains to be elucidated.

Objective To determine the in vitro and in vivo effects and mechanism of action of the second-generation ALK inhibitor ceritinib on RMS cell growth.

Methods Effects of ceritinib on cell proliferation, wound healing, cell cycle, and RTK signaling were determined in alveolar and embryonal rhabdomyosarcoma (ARMS, ERMS). In addition, possible synergistic effects of combined treatment with ceritinib and the $\mathrm{Abl} / \mathrm{Src}$ family kinase inhibitor dasatinib were determined.

Results Ceritinib treatment led to decreased cell proliferation, cell cycle arrest, apoptosis, and decreased in vivo tumor growth for the ARMS subtype. ERMS cell lines were less affected and showed no cell cycle arrest or apoptosis. Both subtypes lacked intrinsic ALK phosphorylation, and ceritinib was shown to affect the IGF1R signaling pathway. High levels of phosphorylated Src (Tyr416) were present following
\end{abstract}

Electronic supplementary material The online version of this article (https://doi.org/10.1007/s11523-017-0528-z) contains supplementary material, which is available to authorized users.

Anke E. M. van Erp

anke.em.vanerp@radboudumc.nl

1 Department of Medical Oncology, Radboud University Medical Center, P.O. Box 9101, 6500HB Nijmegen, The Netherlands

2 Clinical Studies, Clinical and Translational Sarcoma/Gene Function, The Institute of Cancer Research, London SW3 6JB, UK

3 The Institute of Cancer Research and The Royal Marsden NHS Foundation Trust, London SW7 3RP, UK ceritinib treatment, making combined treatment with a Src inhibitor a potential treatment option. Combined treatment of ceritinib and dasatinib showed synergistic effects in both ERMS and ARMS cell lines.

Conclusion This study shows that monotherapy with an ALK inhibitor, such as ceritinib, in RMS, has no effect on ALK signaling. However, the synergistic effects of ceritinib and dasatinib are promising, most probably due to targeting of IGF1R and Src.

\section{Key Points}

Anaplastic lymphoma kinase (ALK) targeting remains questionable in rhabdomyosarcoma (RMS)

The efficacy of the ALK inhibitor ceritinib in RMS appears to be dependent on the inhibition of IGF1R

Combination of IGF1R and Src inhibitors show synergy in RMS in vitro

\section{Introduction}

Anaplastic lymphoma kinase (ALK) is a glycosylated, singlechain trans-membrane receptor tyrosine kinase (RTK) of the insulin receptor (InsR) superfamily. ALK was initially identified as part of an oncogenic fusion protein in anaplastic largecell lymphoma, and it has since been shown to be involved in the embryonic nervous system and in tumor development [1, 2]. However, the exact role of ALK in tumor initiation and progression remains elusive. While specific ligands are thought to bind and activate ALK, genetic alterations and protein 
overexpression have also been shown to result in ALK activation in a ligand-independent manner. Downstream signaling activates multiple pathways involved in cell proliferation, survival, and cell cycle progression, including PI3K/Akt, MEK/ ERK, and the JAK-STAT/Cyclin D2 pathways [3-5]. ALK expression has been implicated in several malignancies, including rhabdomyosarcoma (RMS), the most common pediatric soft tissue sarcoma (STS).

RMS is a highly malignant STS seen mostly in children, adolescents, and young adults [6]. RMS has multiple histologically distinct subtypes, of which embryonal RMS (ERMS) and alveolar RMS (ARMS) are the most common among pediatric patients. ERMS is typically observed in young children and has a more favorable outcome compared to ARMS. ERMS frequently shows a gain of chromosomes 2, 8, and 12, loss of heterozygosity at $11 \mathrm{p}$, and a higher mutational load. ARMS has a higher metastatic rate, can present itself throughout childhood and adolescence, and in the majority of cases a characteristic fusion of $P A X 3$ or $P A X 7$ on chromosome 2 to FOXO1 on chromosome 13 occurs, resulting in the oncogenic fusion-protein PAX3/7-FOXO1 [7-9]. A minority of ARMS lack the fusion, presenting with clinical and biological characteristics more resembling ERMS [10]. Despite intensive therapy, the survival of metastatic patients remains poor. In addition, RMS survivors can suffer from immediate and late treatment-associated toxicities, underlining the need for new, targeted treatment strategies $[7,11,12]$.

Pillay et al. were among the first to assess the expression of ALK in RMS. ALK expression was seen in $23 \%$ of cases with the highest expression in ARMS (45\%), compared to ERMS (15\%) and other RMS subtypes (8\%) [13]. ALK expression was later associated with $A L K$ copy number gain, metastatic disease at diagnosis, and in some studies with a worse overall survival (OS) [14-19]. Despite the $A L K$ copy number gain in ALK-positive tumors, true $A L K$ amplification was observed in only a small group of RMS patients [14, 19]. In addition, until recently, no $A L K$ rearrangements or activating mutations were detected in RMS patients, and even now only one case of ERMS was shown to have an EML4-ALK fusion [18]. In line with these findings, full-length ALK was observed in RMS tissue samples. $A L K$ exon deletions resulting in an immature ALK form have been reported. However, the influence of exon deletions on ALK functioning was not further examined [14, 16].

A possible explanation for the higher expression of ALK in ARMS samples could be the high binding affinity of PAX3FOXO1 for the 3rd intron of ALK and its influence on ALK transcription [20]. Some controversy on the correlation of ALK expression with fusion status exists, and several studies could not find a difference in specific ALK gain or ALK expression between fusion-positive and fusion-negative RMS [19, 14, 15]. Furthermore, specific ALK copy number gain could not be correlated with ALK expression or RMS subtype, and it was even suggested that the high expression levels might be the result of the high proliferative rate of the cells $[14,15,21]$. In line with this hypothesis, no endogenous phosphorylation of ALK has been observed in RMS cell lines and activation of ALK could be induced only by the addition of phosphatase inhibitors or agonistic antibodies [16, 22, 23], making a prominent role for ALK in RMS cell growth questionable. Silencing of $A L K$ did not influence RMS growth [18, 24], whereas treatment with ALK inhibitors led to a reduction in cell proliferation and viability in several RMS cell lines $[25,26]$. The latter may be the result of multi-kinase activity of the inhibitors $[22,24]$. Nevertheless, independent of ALK activity, ALK might play a role in metastatic disease, since silencing of ALK led to reduced invasion of RMS cells in vitro, even in a non-phosphorylated state [18].

The majority of clinical trials testing both FDA approved and experimental ALK inhibitors focus on tumor types harboring ALK aberrations. Studies with specific inclusion of ARMS or ERMS are scarce. To the best of our knowledge, only three ongoing studies have specified the inclusion of metastatic ARMS (NCT01548926), ERMS and ARMS patients (NCT02034981) or ALK-positive RMS patients (NCT01742286). Preliminary data of these trials have, however, not shown any response in the included RMS patients (Table S1), which indicates that targeting ALK in RMS does not seem to be very promising in the clinic.

Current studies examining the preclinical effects of ALK in RMS focused on the use of the first-generation ALK inhibitors, which were associated with a more multi-kinase targeting profile $[22,24]$. In addition, so far these agents were tested solely in vitro. The second-generation ALK inhibitor ceritinib has clinical activity in patients with ALK-positive, metastatic non-small cell lung cancer (NSCLC) and was capable of overcoming resistance to the first-generation ALK inhibitor crizotinib $[27,28]$. In order to further elucidate the potential of ALK inhibition in RMS and to determine the efficacy of second-generation ALK inhibitors in these tumors, the effects of ceritinib were determined in ARMS and ERMS models in vitro and on growth of ARMS models in vivo. In addition, we studied whether combined treatment of ceritinib and dasatinib was capable of enhancing the monotherapeutic effects of ALK inhibition in RMS.

\section{Materials and Methods}

\subsection{Reagents}

The ALK inhibitor ceritinib (LDK378) was provided by Novartis (Basel, Switzerland). The multi-tyrosine kinase inhibitor dasatinib (Abl/Src family kinases) was purchased from SelleckChem (Munich, Germany). Compounds were diluted in DMSO or $0.5 \%$ HPMC $/ 0.5 \%$ Tween 80 for in vitro and in vivo experiments, respectively. 


\subsection{Cell Lines and Cell Culture}

PAX3-FOXO1-positive ARMS (Rh30, Rh41) and -negative ERMS (Rh18 and RD) cell lines were generously provided by Dr. Peter Houghton. The Aska cell line was generously provided by Dr. Kazuyuki Itoh. Both ARMS cell lines were cultured in RPMI 1640 medium, RD and Aska cells in DMEM medium, and Rh18 cells in McCoy's 5A medium (all Lonza, Breda, The Netherlands). Media were supplemented with $10 \%$ fetal bovine serum (Gibco, ThermoFisher, Breda, The Netherlands) and 1\% Penicillin/Streptomycin (Lonza). Cells were cultured in a humidified atmosphere of $5 \% \mathrm{CO}_{2} /$ $95 \%$ air at $37^{\circ} \mathrm{C}$.

\subsection{Cell Viability Assay}

Cell viability was assessed in MTT assays as previously described [29]. RMS cells were seeded at 5000 cells (RD, Rh30, and Rh41), 3000 cells (Rh18), or 10,000 cells (Aska) in $100 \mu \mathrm{l} /$ well. Experiments were repeated in triplicate and $\mathrm{IC}_{50}$-values were calculated with GraphPad Prism Version 5.03 software.

\subsection{Wound Healing Assay and Cell Cycle Analysis}

Wound healing assays and cell cycle analysis were performed as previously described [29, 30]. For the wound healing assays, RMS cells were seeded at $0.6-1.5 \times 10^{6} \mathrm{cells} / 2 \mathrm{ml} / \mathrm{well}$, and the cell cycle analysis was performed on a BD FACSCalibur (Franklin Lakes, NJ, USA) flow cytometer.

\subsection{PathScan Analysis}

The human PathScan RTK signaling antibody array kit (Cell Signaling Technology, cat.\#7949, Danvers, MA, USA) was used according to the manufacturer's protocol. Lysates of cells treated with or without ceritinib $(2.5 \mu \mathrm{M})$ for $24 \mathrm{~h}$ were used. Images were analyzed with the Odyssey Infrared Imaging System (LI-COR Biosciences, Lincoln, NE, USA) and Odyssey Application Software (version 3.0.30). Kinase phosphorylation was calculated with the following equation: (Et, 1 or Et, $2 / \bar{x} \mathrm{Epc})^{*} 100 \%$. Both spots on the array of a particular target (Et,1 and Et,2) were individually divided by the average of all positive control spots on the array ( $\bar{x}$ Epc) and representative percentages were calculated. Phosphorylation is presented as relative phosphorylation.

\subsection{Western Blot}

Western Blot analysis was performed as previously described [29]. A detailed list of monoclonal antibodies used in this study can be found in the electronic supplementary material.
The ALK-rearranged synovial sarcoma cell line Aska was used a positive control for ALK and pALK analysis [23]. Images were analyzed with the Odyssey Infrared Imaging System and Odyssey Application Software.

\section{7 siRNA Experiments}

Cells were transfected with $25 \mathrm{nM}$ of a scrambled control siRNA, or specific anti-ALK or anti-IGF1R siRNA (Dharmacon, Lafayette, CO, USA) using Lipofectamine 2000 transfection reagents and opti-MEM medium according to the manufacturer's protocol (Invitrogen, Carlsbad, CA, USA). Following transfection, the cells were either lysed for Western Blot analysis or cell viability was determined by MTT assay. Cell viability experiments were performed in triplicate and the $p$-value was calculated (Student's t-test) with GraphPad Prism Version 5.03 software. ${ }^{*} p<0.05$, $* * p<0.01, * * * p<0.001$.

\subsection{In Vivo Experiments}

Female Balbc/nude mice (6-8 weeks) were subcutaneously implanted with Rh41 RMS xenografts, and experiments were started at a tumor size of $0.1-0.6 \mathrm{~cm}^{3}$ (1-2 weeks after implantation). Ceritinib was administered daily at $25 \mathrm{mg} / \mathrm{kg}$ or $50 \mathrm{mg} / \mathrm{kg}$ by oral gavage. Each therapy group $(n=7)$ was treated for 4 weeks. Tumor growth was monitored by caliper measurements in three dimensions (length (l), width (w) and height (h); all maximum diameter) twice weekly. Tumor size was calculated using the formula:4/3 $\pi \times 1 /$ $2 \times w / 2 \times h / 2$. Mice were euthanized on day 28. If treatment was scheduled on day 28 , mice were euthanized 2 $4 \mathrm{~h}$ post injections. Tumor sizes are depicted as relative tumor volume $(\mathrm{RTV}=$ tumor volume at any time $(\mathrm{Vt}) /$ tumor volume at $t=0(\mathrm{Vt} 0))$. All applicable international, national, and institutional guidelines for the care and use of animals have been followed. All procedures performed in studies involving animals were in accordance with the ethical standards of the animal ethical committee of the Radboud University, Nijmegen, The Netherlands.

\subsection{Immunohistochemistry (IHC)}

IHC of tumor xenografts was performed to evaluate vascularization (CD34), proliferation (Ki67), apoptosis (Caspase-3), and effects on the PI3K/Akt and MEK/ERK pathways (pAkt/pERK). A detailed description of the methodology and analysis can be found in the supplementary material.

\subsection{Combination Indices}

Drug synergy of combined ceritinib and dasatinib treatment was assessed by calculation of the combination 
index (CI) and dose reduction index (DRI). The CI and DRI were calculated with CompuSyn software according to the manufacturer's recommendation [31, 32]. Concentrations equal to $1 / 4 x$ IC50 - 4xIC50-values of ceritinib and dasatinib were combined in a constant ratio. The monotherapy and combination therapy effects on cell viability were determined in three independent experiments and an average fraction of cell viability affected (FA)-value was used for further calculations. Synergism of the combination treatment is represented in an isobologram and Table 2. The line represents an additive effect $(\mathrm{CI}=1)$ of the combination at the given FA-value. Points below or above the line represent synergism $(\mathrm{CI}<1.0)$ and antagonism $(\mathrm{CI}>1.0)$, respectively. Points on the $\mathrm{x}$-axis (ceritinib) and y-axis (dasatinib) represent the dose of the monotherapy necessary to generate the FA-value. DRI values $>1$ represents a favorable dose reduction in the combination treatment compared to the monotherapy dose.

\section{Results}

\subsection{Cell Viability and Cell Migration}

Ceritinib affected the viability of all RMS cell lines in a dosedependent manner (Fig. 1, Table 1). ARMS cell lines (Rh41, Rh30) showed a higher sensitivity compared to ERMS cell lines (RD, Rh18), but not as high as the Aska cell line (positive control). IC50-values were 0.50 and $0.30 \mu \mathrm{M}$ for Rh30 and $\mathrm{Rh} 41$, and 0.87 and $1.0 \mu \mathrm{M}$ for $\mathrm{RD}$ and $\mathrm{Rh} 18$, respectively. Ceritinib treatment did not affect the migratory ability in any of the cell lines (data not shown).

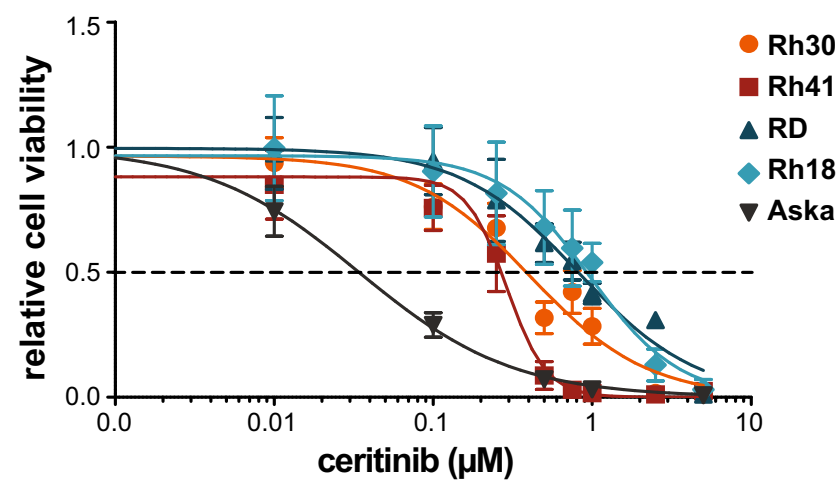

Fig. 1 The effects of ceritinib treatment on cell viability in ARMS and ERMS cell lines. Cells were treated with $0-5 \mu \mathrm{M}$ ceritinib for $72 \mathrm{~h}$ ( $\mathrm{Rh} 30$, RD), $120 \mathrm{~h}$ (Rh41), or $144 \mathrm{~h}$ (Rh18, Aska) and cell viability was assessed. The y-axis represents relative cell viability compared to non-treated cells (control). Effects on cell viability were determined in triplicate. Values are presented as mean $\pm \mathrm{SD}$. Dotted line represents the IC50-value. The human synovial sarcoma cell line Aska with constitutive ALK phosphorylation was used as a positive control
Table 1 Ceritinib and dasatinib IC50-values for ARMS and ERMS cell lines

\begin{tabular}{|c|c|c|c|c|}
\hline \multirow[t]{3}{*}{ Treatment } & \multicolumn{4}{|c|}{ Cell line $\left(\mathrm{IC}_{50} \pm \mathrm{SD}\right)$} \\
\hline & \multicolumn{2}{|l|}{ ARMS } & \multicolumn{2}{|l|}{ ERMS } \\
\hline & $\mathrm{Rh} 30$ & Rh41 & $\mathrm{RD}$ & Rh18 \\
\hline Ceritinib $(\mu \mathrm{M})$ & $0.50 \pm 0.19$ & $0.30 \pm 0.09$ & $0.87 \pm 0.02$ & $1.0 \pm 0.71$ \\
\hline Dasatinib $(\mu \mathrm{M})$ & $0.64 \pm 0.04$ & $6.44 \pm 0.43$ & $6.88 \pm 2.87$ & $0.31 \pm 0.18$ \\
\hline
\end{tabular}

ARMS alveolar rhabdomyosarcoma, ERMS embryonal rhabdomyosarcoma, IC50 concentration at which $50 \%$ of the cell viability is affected, $S D$ standard deviation

\subsection{Anaplastic Lymphoma Kinase (ALK) in ARMS and ERMS Cell Lines}

The expression of ALK and phosphorylated ALK (Tyr1507) (pALK) was examined in the ARMS and ERMS cell lines. ARMS cell lines expressed ALK with the highest expression in Rh41 (Fig. 2a). ALK expression was observed at $220 \mathrm{kDa}$, representing full-length ALK, and at $\sim 140 \mathrm{kDa}$, representing an unglycosylated ALK protein [14]. Western Blot analysis did not show pALK in any of the cell lines. Pathscan analysis showed low levels of endogenous pALK in all cell lines (Figs. 2b and c, Supplementary Fig. 2). Rh41 showed the highest level of pALK and phosphorylation was proportional to the level of ALK expression. All cell lines showed a correlation between ceritinib sensitivity and ALK expression levels (Table 1, Fig. 2a).

\subsection{Mechanism of Action of Ceritinib in RMS Cells}

The level of response (IC50 $<1 \mu \mathrm{M}$ ) and lack of intrinsic ALK activity in the cell lines suggested an alternative target for ceritinib in RMS cell lines. In order to investigate the mechanism of action of ceritinib in both ARMS and ERMS cells, we determined the dose required to affect downstream signaling after $24 \mathrm{~h}$ of treatment, with a focus on the oncogenic PI3K/Akt and MEK/ERK pathways. As $24 \mathrm{~h}$ treatment with $2.5 \mu \mathrm{M}$ ceritinib showed a decrease in pAkt but not pERK in all cell lines (Supplementary Fig. 3), but higher concentrations led to excessive Rh41 cell death, we considered treatment of $2.5 \mu \mathrm{M}$ ceritinib for $24 \mathrm{~h}$ the optimal dose for all subsequent experiments concerning the evaluation of the mechanism of action of ceritinib.

\subsubsection{PathScan Analysis}

In order to generate a hypothesis about the kinases involved in ceritinib sensitivity in ARMS and ERMS, a phosphorylation screen of 28 RTKs and 11 signaling nodes was performed 
a

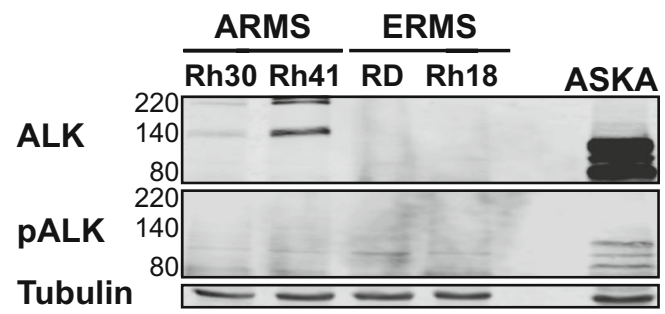

b

ARMS

ERMS

more sensitive

less sensitive

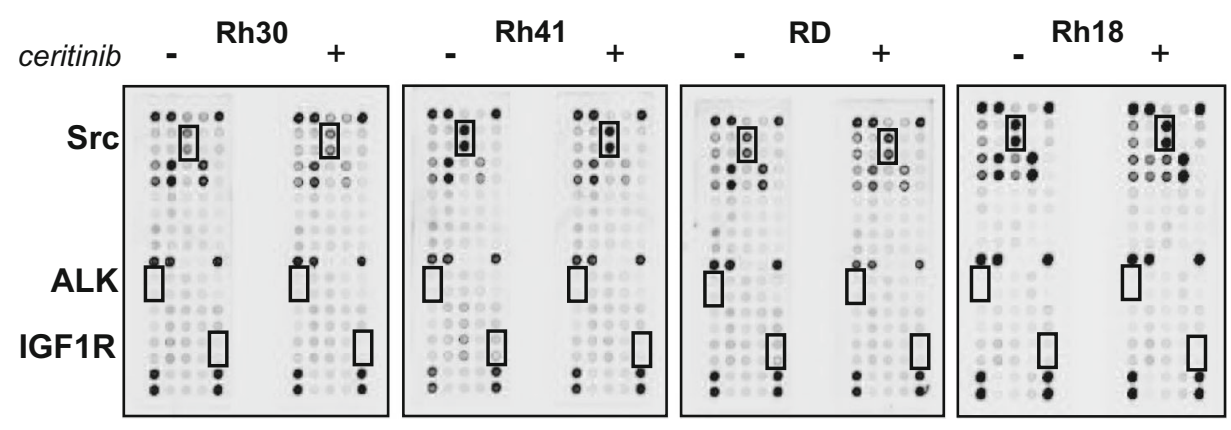

C

\begin{tabular}{|c|c|c|c|c|}
\hline & Rh30 & Rh41 & RD & Rh18 \\
\hline ceritinib & $-\quad+$ & $-\quad+$ & $-\quad+$ & $-\quad+$ \\
\hline ALK & & & & \\
\hline $\begin{array}{r}\text { Axl } \\
\mathrm{c}-\mathrm{Kit} / \mathrm{SCFR}\end{array}$ & & & & \\
\hline EGFR/ErbB1 & & & & \\
\hline $\begin{array}{l}\text { EphA1 } \\
\text { EphA2 }\end{array}$ & & & & \\
\hline $\begin{array}{l}\text { EphA3 } \\
\text { EphB1 }\end{array}$ & & & & \\
\hline 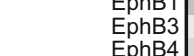 & & & & \\
\hline $\begin{array}{l}\text { Ephi4 } \\
\text { FGFR1 } \\
\text { FGFR3 }\end{array}$ & & & & \\
\hline $\begin{array}{l}\text { FGFR3 } \\
\text { FGFR4 }\end{array}$ & & & & \\
\hline 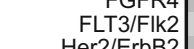 & & & & \\
\hline $\begin{array}{l}\text { Her2//ErbB2 } \\
\text { Her3//rbB33 }\end{array}$ & & & & \\
\hline IGFIR & & & & \\
\hline M-CSFR/CSF-1R & & & & \\
\hline $\mathrm{Met/HGFR}$ & & & & \\
\hline & & & & \\
\hline $\begin{array}{r}\text { Ron/MST1R } \\
\text { Tie2TIEK }\end{array}$ & & & & \\
\hline TrkA/NTRK1 & & & & \\
\hline $\begin{array}{r}\text { TrkB/NTRRK2 } \\
\text { Tyro-3/Dtk }\end{array}$ & & & & \\
\hline & & & & \\
\hline
\end{tabular}

d
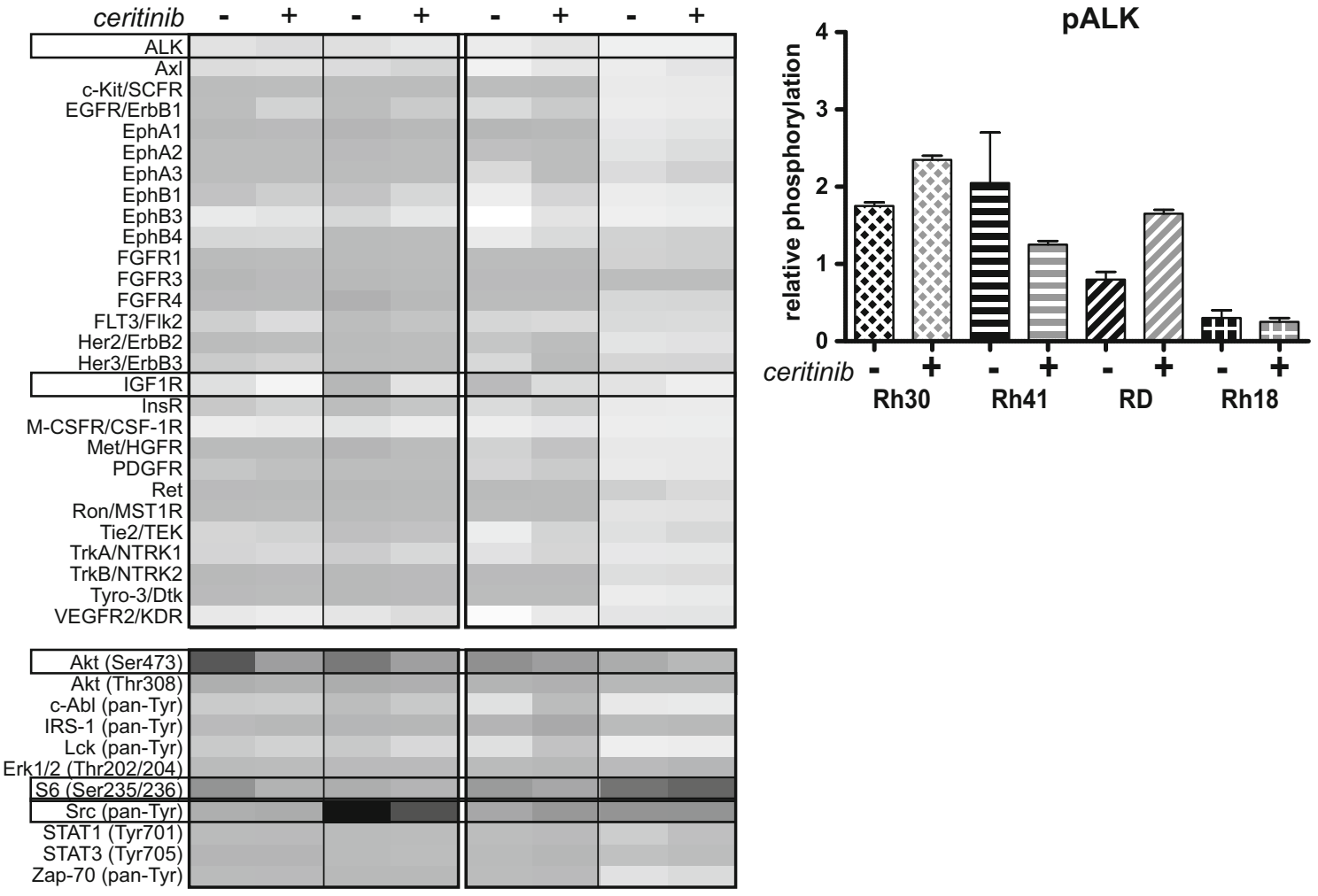

Fig. 2 ALK, pALK expression, and the effect of ceritinib treatment on RTK and signaling protein activity in ARMS and ERMS cell lines. a Endogenous ALK and phosphorylated ALK (pALK) expression in ARMS (Rh30, Rh41) and ERMS (RD and Rh18) cell lines as determined by Western Blot ((p)ALK $=220 / 140 \mathrm{kDa}$, Tubulin $=52 \mathrm{kDa})$. Aska cells were used as a positive control (these cells show a deletion in ALK, leading to constitutive activity). b Phosphorylation of 28 RTKs and 11 signaling proteins was assessed after $24 \mathrm{~h}$ ceritinib treatment $(2.5 \mu \mathrm{M})$ for both ARMS and ERMS cell lines by PathScan analysis. Untreated (-) and treated $(+)$ cells were compared. The boxes represent the location of ALK, IGF1R and Src on the array. $\mathbf{c}$ Heatmap representing the relative phosphorylation (as described in materials and methods) of the examined RTKs and signaling proteins for each cell line. Boxes represent the RTKs/ signaling proteins that were further examined. $\mathbf{d}$ Effect of ceritinib treatment on ALK activity in ARMS and ERMS cell lines (relative ALK phophorylation) as determined by PathScan analysis 
a

pIGF1R

pAkt

pS6
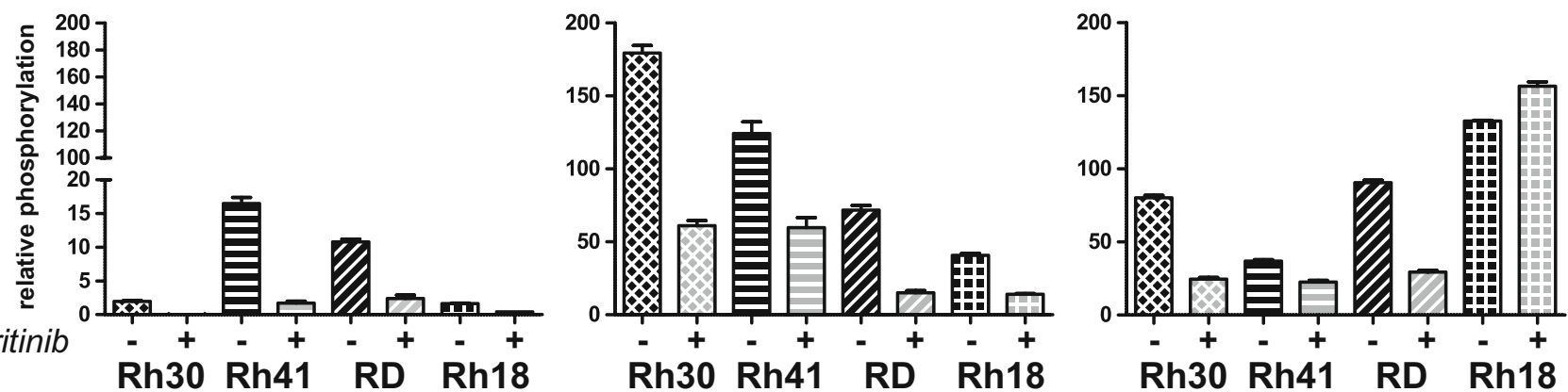

b
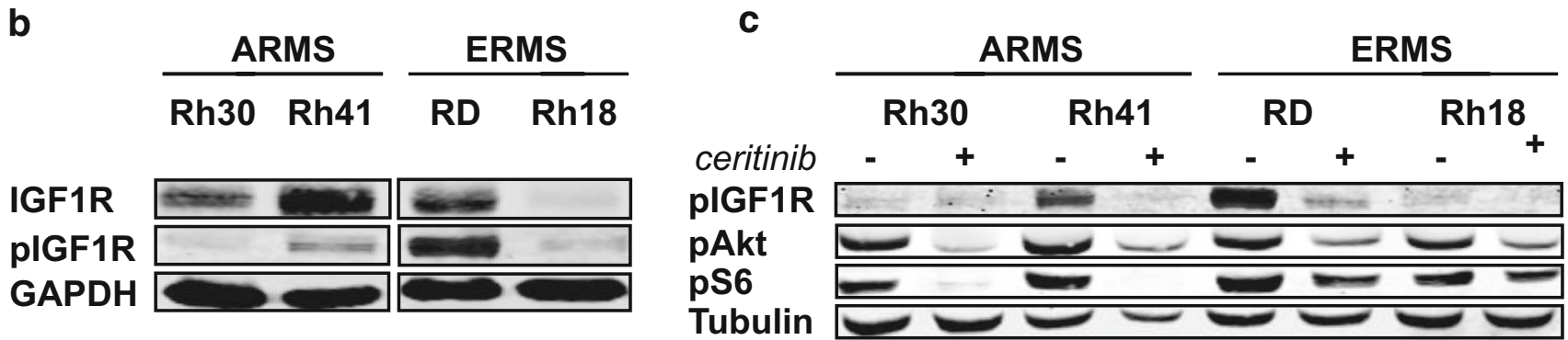

pAkt

pS6

Tubulin

d

Rh41

RD

ASKA

SIRNA $\quad$ NT ALK
ALK
GAPDH

SiRNA

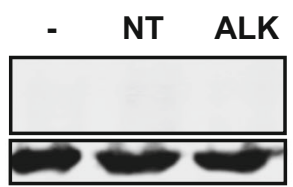

SiRNA

ALK

GAPDH

ALK

GAPDH

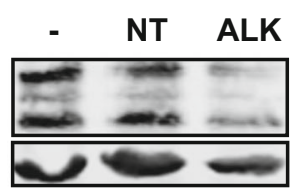

SiRNA

- NT IGF1R

SiRNA

- NT IGF1R

IGF1R

GAPDH

IGF1R

GAPDH

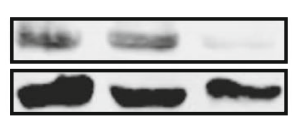

e

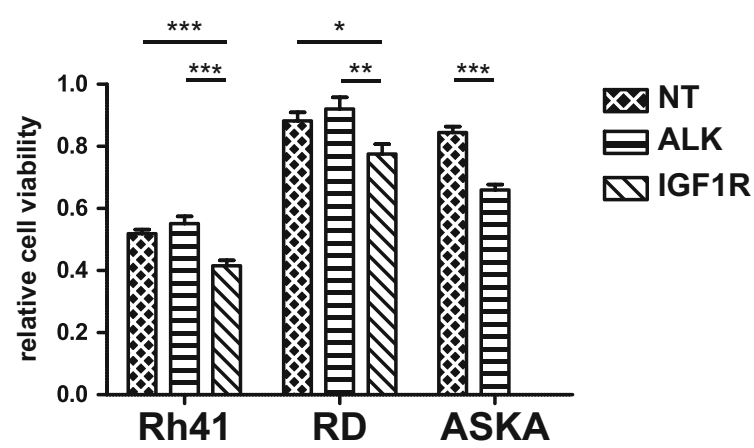

Fig. 3 Effect of ceritinib on insulin-like growth factor-1 receptor (IGF1R) signaling in ARMS and ERMS cell lines. a Effects of ceritinib treatment on pIGF1R, pAkt, and pS6 by PathScan analysis. Relative phosphorylation is shown. $\mathbf{b}$ Endogenous IGF1R and pIGF1R expression in ARMS and ERMS cell lines as determined by Western Blot analysis ((p) IGF1R $=95 \mathrm{kDa})$. $\mathbf{c}$ Confirmation of the effects of ceritinib treatment on pIGF1R, pAkt, and pS6 by Western Blot analysis (pAkt $=60 \mathrm{kDa}$, pS6 $=32 \mathrm{kDa})$. Untreated cells $(-)$ were compared to cells treated with

$2.5 \mu \mathrm{M}$ ceritinib for $24 \mathrm{~h}(+)$. $\mathrm{d}$ ALK and IGF1R expression in the Rh41, $\mathrm{RD}$, and Aska cell line in either untreated $(-)$, scrambled siRNA (NT) treated, or ALK/IGF1R siRNA (ALK/IGF1R) treated cells determined by Western Blot analysis. e Relative cell viability following NT, ALK, or IGF1R siRNA treatment in the Rh41, RD and Aska cell lines. Effects on cell viability were determined in triplicate and untreated (control) cells were set at 1.0.*p<0.05, ** $p<0.01, * * * p<0.001$ 
( $n=1)$ (Fig. 2b, Supplementary Figs. 1 and 2). In contrast to the expected decrease in ALK phosphorylation, ceritinib treatment led to an increase in pALK in Rh30 and RD (Fig. 2c and d). Rh30 and Rh41 showed decreased phosphorylation of 17 and 25 RTKs upon ceritinib treatment, respectively (Fig. 2c, Supplementary Fig. 2). The less sensitive ERMS cell lines showed decreased phosphorylation of 1 or 6 RTKs and increased phosphorylation of 18 (RD) and 4 (Rh18) RTKs upon treatment (Fig. 2c). Both ARMS cell lines showed a decrease in EGFR, FGFR, Her2/3, InsR, Ron, MST1R, TrkB, and Tyro-3 phosphorylation, which could not be observed for ERMS cell lines (Fig. 2c, Supplementary Fig. 2). In contrast, ceritinib treatment led to an increase in phosphorylation of multiple members of the ephrin receptor family, Tie2, and VEGFR2 in the ERMS cell lines. Downstream signaling most prominently decreased in Rh41 and increased in RD (Fig. 2c, Supplementary Fig. 2).

\subsubsection{IGF1R Signaling}

Ceritinib treatment led to a decrease in pIGF1R and downstream pAkt (Ser473) in all cell lines (Figs. 2c and 3a). S6 ribosomal protein phosphorylation (pS6) was decreased in Rh41, Rh30 and RD, and increased in Rh18 (Fig. 3a). Western Blot analysis confirmed baseline IGF1R expression in Rh30, Rh41 and RD, baseline pIGF1R in Rh41 and RD (Fig. 3b) and the effects on pIGF1R, pAkt and pS6 following treatment (Figs. 2c and 3c). IGF1R expression in Rh18, and pIGF1R in Rh18 and Rh30 were too low to be detected by Western Blot analysis (Fig. 3b). Knockdown of IGF1R by siRNA led to a significant decrease in cell viability in the Rh41 and RD cell lines. Knockdown of ALK did not show this effect except in the pALK-positive Aska cell line (Fig. 3d and e).

\subsubsection{Cell Cycle Arrest and Apoptosis}

Investigation of the possible effects of ceritinib treatment on the cell cycle showed a G0/G1 cell cycle arrest in Rh30. Rh18 showed a decreased S-phase, but no clear cell cycle arrest. Rh41 and RD were not affected (Fig. 4a). Rh41 and Rh30 showed apoptosis-associated PARP cleavage upon treatment, which could not be observed in RD and Rh18 (Fig. 4b).

\subsection{Effects of Ceritinib Treatment on Rh41 Tumor Growth In Vivo}

In order to investigate the mechanism of action of ceritinib in vivo, the most ceritinib-sensitive Rh41 model was selected. Ceritinib efficacy was examined on subcutaneously implanted $\mathrm{Rh} 41$ xenografts in a dose-response experiment with daily treatment of 0,25 or $50 \mathrm{mg} / \mathrm{kg}$ ceritinib for 28 days. A reduction of tumor growth was observed after approximately 2 weeks of treatment in both treatment groups, which continued up to 28 days of treatment (relative growth control $55.2 \pm 21.9$ vs. $25 \mathrm{mg} / \mathrm{kg} 21.2 \pm 8.1, p<0.01$ or $50 \mathrm{mg} / \mathrm{kg} 21.3 \pm 5.9, p=0.01$ ) (Fig. 5). Further evaluation of tumor characteristics showed no difference in proliferation or vascularization between the treatment groups and controls or between the treatment groups, and no differences in pERK and pAkt levels (data not shown). There
Fig. 4 Cell cycle arrest and PARP cleavage in ARMS and ERMS cell lines upon ceritinib treatment. a Cells were treated with ceritinib for $24 \mathrm{~h}$ and stained with propidium iodide (PI). The level of PI was determined and the percentage of cells in the G0G1, S, or G2-M phase of the cell cycle was quantified by FACS analysis. $* p<0.05, * * p<0.01$, $* * * p<0.001$. b Effects of $24 \mathrm{~h}$ ceritinib treatment on PARP cleavage by Western Blot analysis $(\mathrm{PARP}=116 \mathrm{kDa}$, cleaved $\mathrm{PARP}=89 \mathrm{kDa}$ )

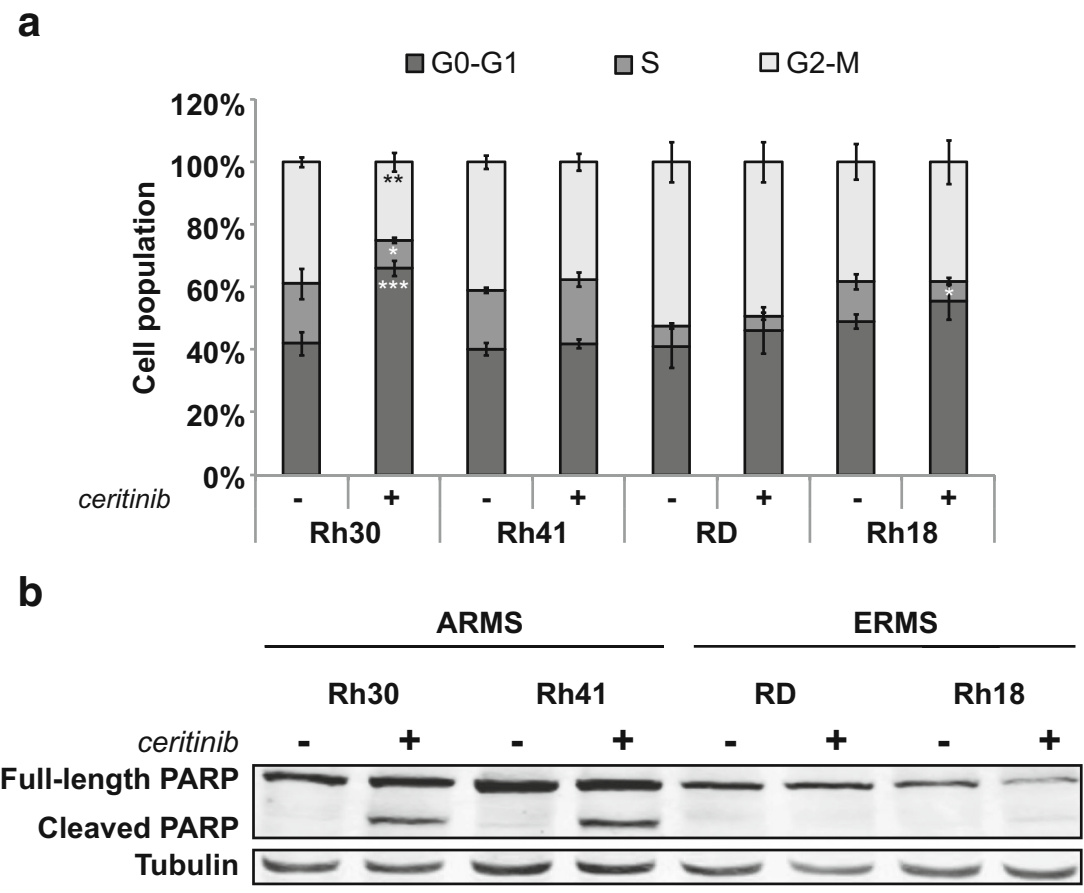


Fig. 5 Treatment effects on ARMS tumor xenograft growth. Nude mice bearing Rh41 human xenografts were treated for 28 days with either vehicle (control) or ceritinib (25 or $50 \mathrm{mg} / \mathrm{kg}$ ). a Relative tumor volume of control and treated mice. Values are presented as mean \pm SD. b Graphic representation of relative tumor growth for the control and treated ( 25 or $50 \mathrm{mg} / \mathrm{kg}$ ) groups.

Quantitative

immunohistochemical analysis of caspase-3 levels for all three treatment groups. Values are presented as mean $\pm \mathrm{SD}$, $* p<0.05, * * p<0.01$
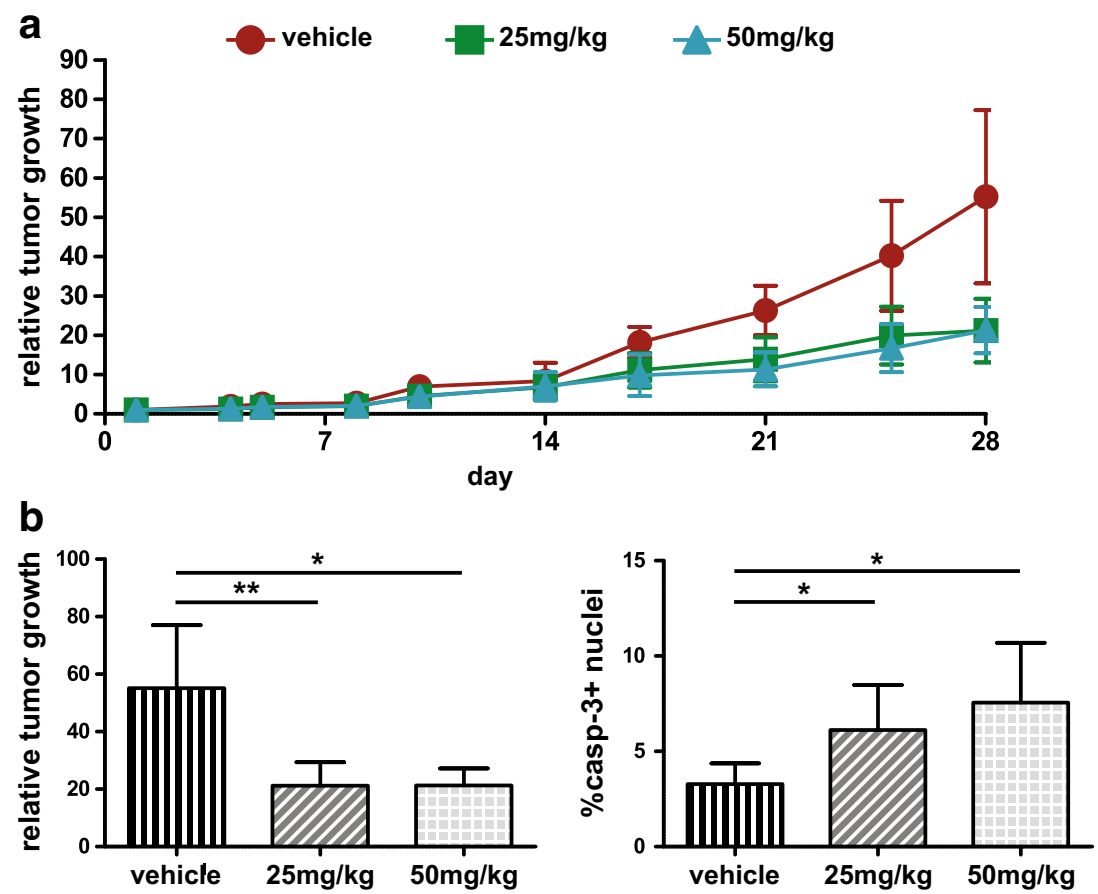

was a significant increase in caspase- 3 expression in both the 25 and $50 \mathrm{mg} / \mathrm{kg}$ treatment groups (Fig. 5b). Of note, when only the outliers ( $n=2 /$ group) of the control and $50 \mathrm{mg} / \mathrm{kg}$ treatment groups were considered (relative growth control $77.0 \pm 0.3$ vs. $50 \mathrm{mg} / \mathrm{kg} 16.6 \pm 3.3, p<0.01$ ) (Supplementary Fig. 4), a significant decrease in proliferation was present in the treated group (Ki67, $p=0.021$ ). Trends towards higher caspase-3 expression $(p=0.0604)$ and more vascularization in the treated group were observed as well in these outliers (CD34, $p=0.077)$.

\subsection{Src Signaling and Combination Experiments}

All cell lines showed high levels of pSrc (pan-Tyr) before and after ceritinib treatment (Fig. 2c, Supplementary Fig. 2). Ceritinib did not affect pSrc in Rh30 and Rh18. RD showed a slight increase and Rh41 showed a decrease upon treatment but remained the cell line with the highest level of pSrc (Fig. 6a). Western Blot analysis of autophosphorylationassociated pSrc (Tyr416) revealed, again, high levels of pSrc before and after ceritinib, making the combination of ceritinib and the Abl/Src inhibitor dasatinib of interest (Fig. 6b). IC50values of dasatinib showed differences in sensitivity between the cell lines (Table 1). Rh30 and Rh18 showed IC50-values $<0.5 \mu \mathrm{M}$, whereas Rh41 and RD showed an IC50 of $>5 \mu \mathrm{M}$.

Combined treatment of dasatinib and ceritinib showed a trend towards higher cell viability inhibition when compared to the individual monotherapies (Fig. 7a). Possible synergistic effects were further evaluated and synergism was observed in all cell lines (Fig. 7b), even at low dose combinations (data not shown). The Rh30 and RD cell lines showed CI-values $<1$

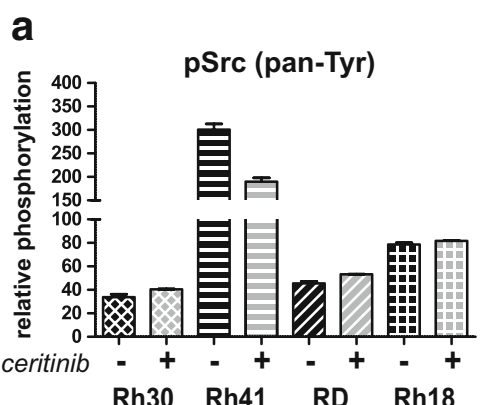

Fig. 6 Effects of ceritinib treatment on Src phosphorylation in ARMS and ERMS cell lines. a Effects of treatment on pan-tyrosine phosphorylation of Src (pSrc) by PathScan analysis. Relative phosphorylation is shown. b Effects of $24 \mathrm{~h}$ ceritinib treatment on $\mathrm{pSrc}$ (Tyr416) as analyzed

b

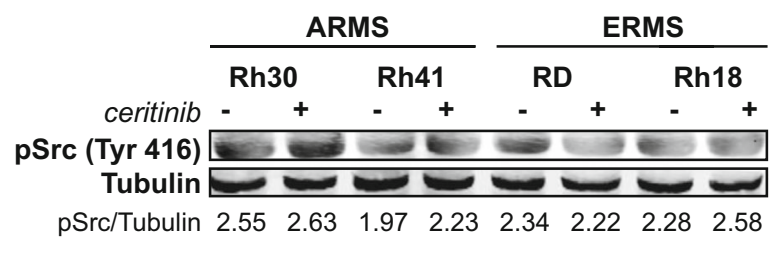

by Western Blot (pSrc $=60 \mathrm{kDa})$. Untreated cells $(-)$ were compared to cells treated with $2.5 \mu \mathrm{M}$ ceritinib (+). Quantification of fluorescent signal is given below, representing pSrc divided by Tubulin 
Fig. 7 Evaluation of synergism for dasatinib and ceritinib combination treatment in ARMS and ERMS cell lines. a ARMS (Rh41, Rh30) and ERMS (RD, $\mathrm{Rh} 18)$ cell lines were treated with a range of dasatinib and ceritinib concentrations $(1 / 4 \times$ IC50 $-4 \times$ IC50) either as mono- or combined therapy and the fraction of the cell viability (FA-value) affected by the treatment was calculated. Bars represent the mean $\pm \mathrm{SD}$. X-axis represents the fraction of the IC50-value used for treatment. b Isobolograms show synergistic effects of the combination treatment at a FAvalue of $0.5,0.75$ and 0.9 for each cell line. Points on the $\mathrm{x}$-axis (ceritinib) and y-axis (dasatinib) represent monotherapy doses necessary to generate the given FA-value. Line connecting the $x$ and $y$-axis represent an additive effect of the combination $(\mathrm{CI}=1.0)$. Points below and above the line represent synergism $(\mathrm{CI}<1.0)$ and antagonism $(\mathrm{CI}>1.0)$, respectively a $\mathbf{W}$ dasatinib

ceritinib

$\Delta \nabla$ dasatinib + ceritinib
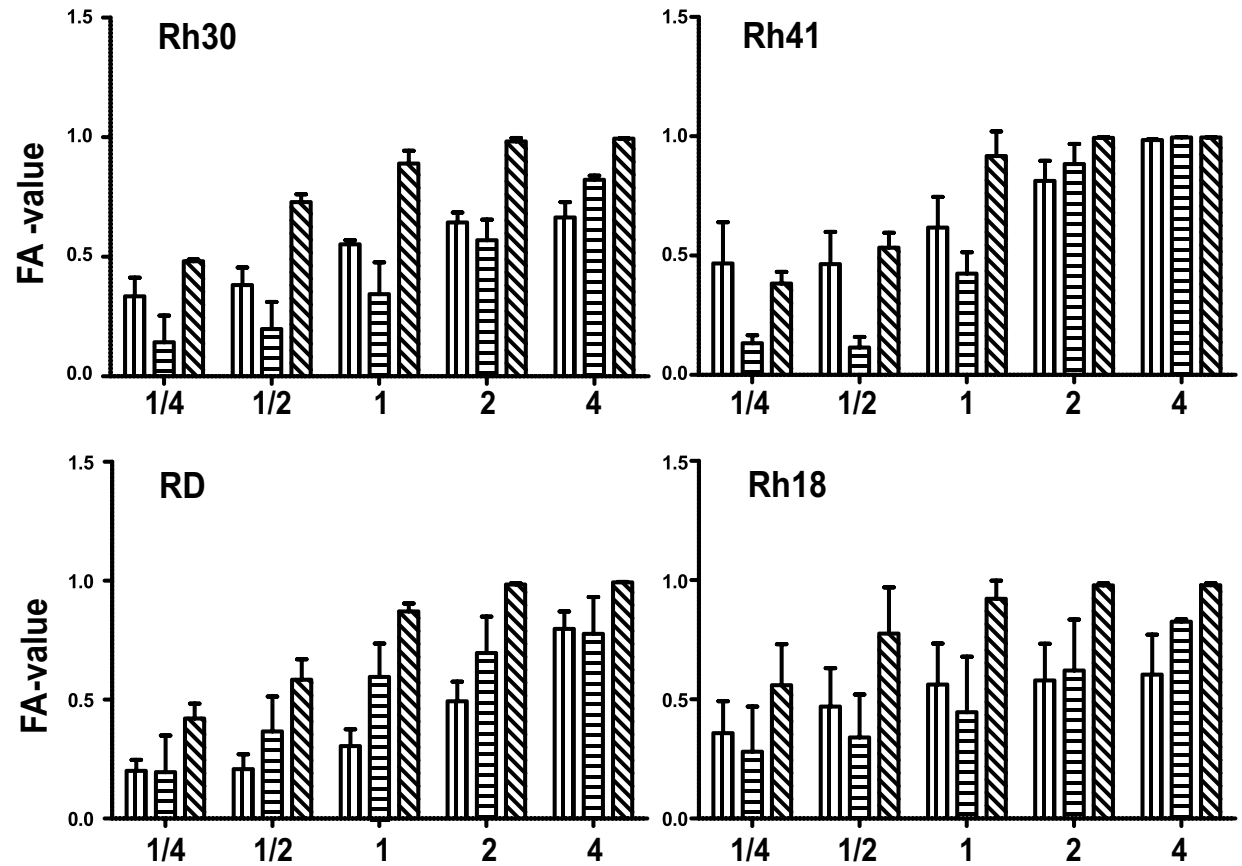

b

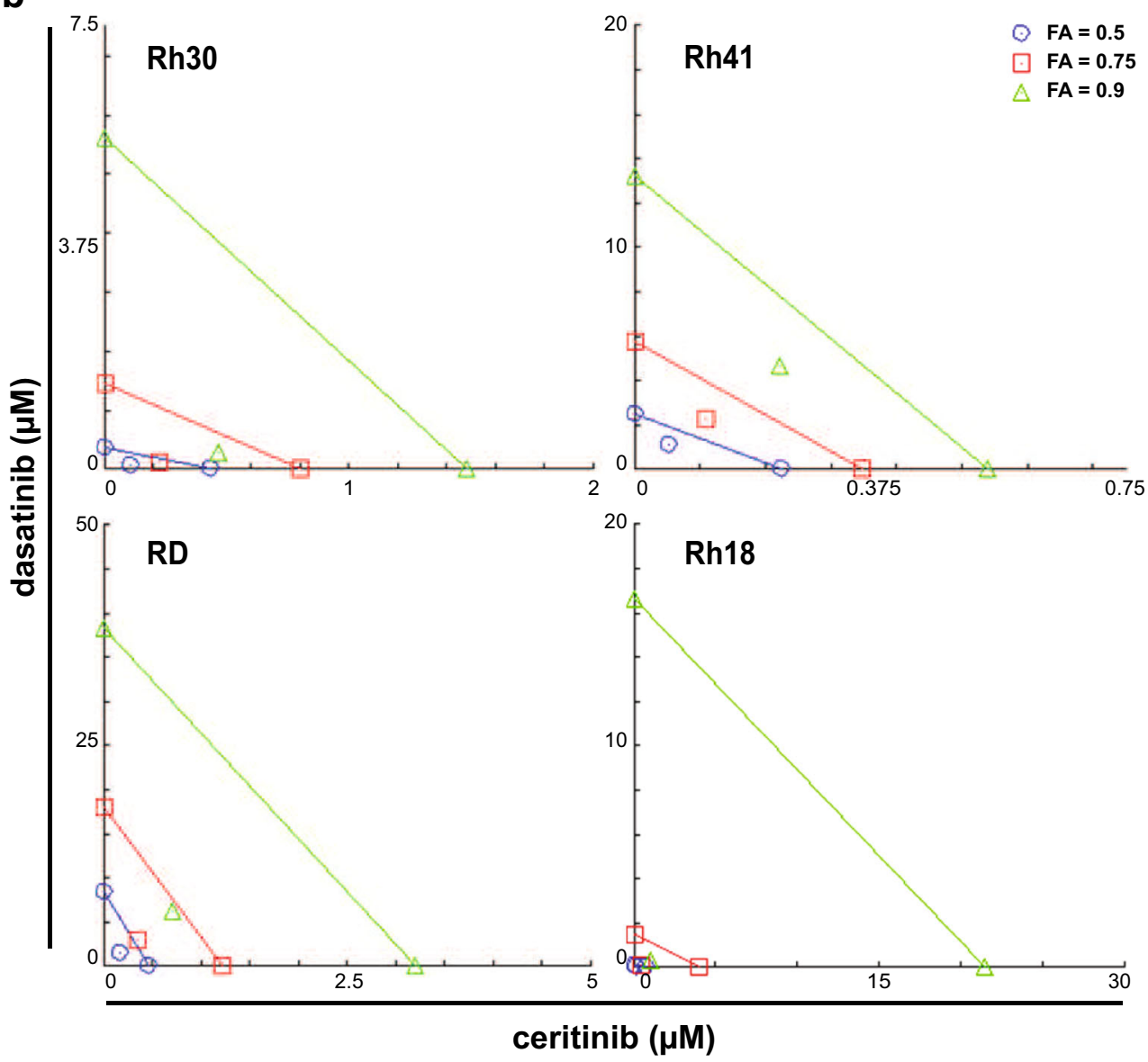


(0.342-0.563) with a favorable dose reduction for both dasatinib and ceritinib (DRI > 1) at all examined combinations (Table 2, Fig. 7b). Rh41 showed lower levels of synergism (0.681-0.831) and dose reduction compared to other cell lines. However, the combination of dasatinib and ceritinib was favorable in this cell line. Rh18 showed strong synergism $(\mathrm{CI}<0.3)$ at higher inhibitory concentrations with a strong DRI indicating that, in particular, higher inhibitory concentrations generate strong synergistic effects (Table 2, Fig. 7b).

\section{Discussion}

In this study, we aimed to elucidate the mechanism of action and the potential of ALK inhibition in RMS. The underlying reason for this is that although several clinical studies are evaluating the effects of ALK-targeting in RMS patients, the exact role of ALK in these tumors remains questionable. No effects have been reported in RMS in the clinic so far, urging the need to critically re-evaluate the potential of ALK as a target for RMS therapy. Previous research into the role of ALK in RMS has led to the discovery of full-length ALK in RMS, with a predilection for the ARMS phenotype. Accordingly, a similar preference for ARMS was observed in our study with higher sensitivity to ALK-targeted therapy. However, instead of the expected decrease in ALK activity upon treatment, nearly undetectable endogenous levels of pALK were observed. This lack of intrinsic ALK activity was previously observed in ARMS cell lines [22, 23]. Peron et al. further showed that the activation of ALK is dependent on the induction of autophosphorylation by agonistic antibodies and the activity of cytoplasmic phosphatases [22]. However, the cytotoxicity seen upon treatment does suggest an alternative target of ceritinib may be present in ARMS and ERMS cell lines.

Table 2 Combination index (CI) and dose reduction index (DRI) for the combination treatment of dasatinib and ceritinib in ARMS and ERMS cell lines

\begin{tabular}{|c|c|c|c|c|}
\hline \multirow[t]{2}{*}{ FA-value } & & \multicolumn{3}{|c|}{ CI (DRI dasatinib, ceritinib) } \\
\hline & & 0.5 & 0.75 & 0.9 \\
\hline \multirow[t]{2}{*}{ ARMS } & Rh30 & $0.415(5.91 ; 4.07)$ & $0.370(10.9 ; 3.59)$ & $0.365(19.9 ; 3.18)$ \\
\hline & $\mathrm{Rh} 41$ & $0.681(2.24 ; 4.27)$ & $0.710(2.51 ; 3.21)$ & $0.769(2,81 ; 2,42)$ \\
\hline \multirow[t]{2}{*}{ ERMS } & $\mathrm{RD}$ & $0.563(5.48 ; 2.62)$ & $0.464(5.83 ; 3.42)$ & $0.385(6.21 ; 4.46)$ \\
\hline & Rh18 & $0.619(2.54 ; 4.45)$ & $0.187(11.8 ; 9.74)$ & $0.065(55.1 ; 21.3)$ \\
\hline
\end{tabular}

Calculated by CompuSyn software

CI Combination index, DRI Dose reduction index, FA-value fraction of cell viability affected by treatment, $A R M S$ alveolar rhabdomyosarcoma, ERMS embryonal rhabdomyosarcoma
In line with previous findings [33], ceritinib led to a decrease in IGF1R activity in all cell lines. Cellular signaling activity was decreased by inhibition of the PI3K/Akt/S6 pathway with the exception of one ERMS cell line. In this cell line a decrease in pAkt was accompanied by an increase in S6 activity. pS6 is regulated by both the PI3K/Akt and the MEK/ERK pathways [34, 35]. The ERMS cell lines showed an increased ERK activity post ceritinib treatment, possibly explaining the observed increase in pS6. The role of IGF1R in the mechanism of action of ceritinib was further investigated by silencing of IGF1R and ALK. IGF1R knockdown reduced viability in the RMS cell lines, whereas knockdown of ALK had no effect. Of note, the Aska cell line with constitutively active ALK did show reduced viability following ALK siRNA treatment. This further shows that the reduction in cell viability in RMS cell lines upon ceritinib treatment is likely dependent on decreased IGF1R activity, rather than ALK activity.

Further examination of the mechanism of action of ceritinib showed a clear distinction between ARMS and ERMS. Ceritinib treatment predominantly increased RTK phosphorylation in ERMS compared to decreased RTK phosphorylation in ARMS. In addition to the increased phosphorylation, the lack of cell cycle arrest and apoptosis strengthens the idea that upon ceritinib treatment, ERMS cells increase phosphorylation of compensatory pathways to prevent cell death. ARMS, on the other hand, showed a clear induction of apoptosisassociated PARP cleavage and a cell cycle arrest in one cell line (Rh30). No cell cycle arrest was observed in Rh41. This difference might be explained by the p53-status of the ARMS cell lines. Rh41 harbors a 53 (c. $700 \_712$ del) mutation, while $\mathrm{Rh} 30$ is p53 wild-type. p53 is the main regulator of the G1 checkpoint, and loss of p53 leads to the loss of the G0/G1 checkpoint [36]. Hypothetically, the altered oncogenic signaling caused by ceritinib can lead to cellular stress and induce the expression of $\mathrm{p} 53$ in $\mathrm{Rh} 30$, resulting in a G0/G1 cell cycle arrest and induction of apoptosis [36, 37]. In Rh41, a G0/G1 arrest cannot be induced and the cell cycle is continued. However, upon cellular stress the lack of p53 can lead to premature exit of the cells from the G2 to M phase. This premature exit of the cell might prevent proper mitosis and lead to the induction of cell death $[36,38]$.

Based on the current results, it can be said that ceritinib monotherapy has a greater effect on ARMS tumor cell growth compared to ERMS. In vivo, ARMS xenograft growth was inhibited by ceritinib treatment with a significant increase in caspase-3 levels. The detected increase of caspase-3, in addition to the in vitro observed increased PARP cleavage, suggest that the effect of ceritinib on cell viability is mediated by caspase-dependent apoptosis [39]. Due to large variations in tumor volume in all treatment groups, the mechanism of action of ceritinib in vivo was difficult to examine. Interestingly, when only the outliers of the control and $50 \mathrm{mg} / \mathrm{kg}$ treatment 
groups were further evaluated, a significant decrease in proliferation and a trend towards higher caspase- 3 levels was observed, indicating that ceritinib treatment in vivo can reduce tumor growth in a manner similar to that established in vitro. However, no complete tumor loss was observed upon treatment, making monotherapy with ceritinib an unlikely treatment option for ARMS.

In order to determine whether combination treatment could enhance the anti-tumor effect of ceritinib, combined treatment with the Abl/Src inhibitor dasatinib was examined for both ARMS and ERMS in vitro. Sre is known to modulate the activity of multiple signaling pathways by interaction with both receptors at the cell membrane and downstream signaling proteins [40]. Even though it was one of the first identified tyrosine kinases, the exact role of Src in oncogenesis is still not clear [41]. Src activity is mediated via the phosphorylation of multiple tyrosine kinase domains with opposing functions. Phosphorylation at Tyr527/Tyr530 leaves Src in an inactive conformation, while dephosphorylation of this domain leads to conformational changes and allows the autophosphorylation at Tyr416/Tyr419 and the binding and phosphorylation of Src substrates [41]. Since all cell lines showed high levels of pSrc (Tyr416), even following ceritinib treatment, and Src is known to be of importance in sarcoma and was previously shown to increase following IGF1R treatment in RMS, the combination of ceritinib with dasatinib was considered of interest [42, 43]. The synergistic effects and favorable dose reduction indices suggest the combination of dasatinib and ceritinib may be favorable in both ARMS and ERMS cell lines.

The current study contributes to the hesitations concerning ALK targeting in RMS. Despite the clear distinction between ARMS and ERMS in sensitivity to ceritinib and the in vivo decrease in tumor growth, the lack of intrinsic ALK activity and the lack of cell growth reduction following ALK knockdown cast doubt on the role of ALK in RMS tumorigenesis. Moreover, ceritinib was shown to inhibit IGF1R activity. Unfortunately, clinical trials testing IGF1R inhibitors in RMS have shown limited results as well, making a monotherapeutic treatment with either ceritinib or more specific IGF1R inhibitors undesirable $[44,45]$. However, the synergistic effect of the in vitro combination of ceritinib and the Abl/Src kinase family inhibitor dasatinib does underline the potential of combined IGF1R and Src targeted therapy in both ARMS and ERMS.

\footnotetext{
Acknowledgements The authors would like to thank Dr. J. van der Laak for the optimization of the quantitative microscopy analysis, the biotechnicians of the central animal facility of the Radboud University Nijmegen, The Netherlands for their assistance in the animal procedures, K. Lenting, MSc. for her assistance in the siRNA experiments, Novartis Pharmaceuticals (Basel, Switzerland) for providing ceritinib (LDK378), and the Pediatric Preclinical Testing Program for generously providing the rhabdomyosarcoma cell lines and xenografts.
}

\section{Compliance with Ethical Standards}

Funding This study was funded by Novartis Pharmaceutical (Basel, Switzerland).

Conflict of Interest Authors van Erp, Hillebrandt-Roeffen, Fleuren and van Houdt declare that they have no conflict of interest. Authors VersleijenJonkers and van der Graaf have received a research grant from Novartis, paid to the institution (Radboudumc, Nijmegen, The Netherlands).

Open Access This article is distributed under the terms of the Creative Commons Attribution-NonCommercial 4.0 International License (http:// creativecommons.org/licenses/by-nc/4.0/), which permits any noncommercial use, distribution, and reproduction in any medium, provided you give appropriate credit to the original author(s) and the source, provide a link to the Creative Commons license, and indicate if changes were made.

\section{References}

1. Morris SW, Kirstein MN, Valentine MB, Dittmer KG, Shapiro DN, Saltman DL, et al. Fusion of a kinase gene, ALK, to a nucleolar protein gene, NPM, in non-Hodgkin's lymphoma. Science. 1994;263(5151):1281-4.

2. Morris SW, Naeve C, Mathew P, James PL, Kirstein MN, Cui X, et al. ALK, the chromosome 2 gene locus altered by the $t(2 ; 5)$ in non-Hodgkin's lymphoma, encodes a novel neural receptor tyrosine kinase that is highly related to leukocyte tyrosine kinase (LTK). Oncogene. 1997;14(18):2175-88.

3. Hallberg B, Palmer RH. The role of the ALK receptor in cancer biology. Ann Oncol. 2016;27 Suppl 3:iii4-iii15.

4. Chiarle R, Voena C, Ambrogio C, Piva R, Inghirami G. The anaplastic lymphoma kinase in the pathogenesis of cancer. Nat Rev Cancer. 2008;8(1):11-23.

5. Guan J, Umapathy G, Yamazaki Y, Wolfstetter G, Mendoza P, Pfeifer K, et al. FAM150A and FAM150B are activating ligands for anaplastic lymphoma kinase. Elife. 2015;4:e09811.

6. Van Gaal JC, De Bont ESJM, Kaal SEJ, Versleijen-Jonkers Y, van der Graaf WTA. Building the bridge between rhabdomyosarcoma in children, adolescents and young adults: the road ahead. Crit Rev Oncol Hematol. 2012;82(3):259-79.

7. Egas-Bejar D, Huh WW. Rhabdomyosarcoma in adolescent and young adult patients: current perspectives. Adolesc Health Med Therapeut. 2014;5:115-25.

8. Shern JF, Chen L, Chmielecki J, Wei JS, Patidar R, Rosenberg M, et al. Comprehensive genomic analysis of rhabdomyosarcoma reveals a landscape of alterations affecting a common genetic axis in fusion-positive and fusion-negative tumors. Cancer Discov. 2014;4(2):216-31.

9. Chen L, Shern JF, Wei JS, Yohe ME, Song YK, Hurd L, et al. Clonality and evolutionary history of rhabdomyosarcoma. PLoS Genet. 2015;11(3):e1005075.

10. Parham DM, Barr FG. Classification of rhabdomyosarcoma and its molecular basis. Adv Anat Pathol. 2013;20(6):387-97.

11. Perkins SM, Shinohara ET, DeWees T, Frangoul H. Outcome for children with metastatic solid tumors over the last four decades. PLoS One. 2014;9(7):e100396.

12. Harrison DJ, Schwartz C. Survivorship. J Surg Oncol. 2015;111(5): 648-55.

13. Pillay K, Govender D, Chetty R. ALK protein expression in rhabdomyosarcomas. Histopathology. 2002;41(5):461-7.

14. van Gaal JC, Flucke UE, Roeffen MH, de Bont ES, Sleijfer S, Mavinkurve-Groothuis AM, et al. Anaplastic lymphoma kinase 
aberrations in rhabdomyosarcoma: clinical and prognostic implications. J Clin Oncol. 2012;30(3):308-15.

15. Yoshida A, Shibata T, Wakai S, Ushiku T, Tsuta K, Fukayama M, et al. Anaplastic lymphoma kinase status in rhabdomyosarcomas. Mod Pathol. 2013;26(6):772-81.

16. Bonvini P, Zin A, Alaggio R, Pawel B, Bisogno G, Rosolen A. High ALK mRNA expression has a negative prognostic significance in rhabdomyosarcoma. Br J Cancer. 2013;109(12):3084-91.

17. Lee JS, Lim SM, Rha SY, Roh JK, Cho YJ, Shin KH, et al. Prognostic implications of anaplastic lymphoma kinase gene aberrations in rhabdomyosarcoma; an immunohistochemical and fluorescence in situ hybridisation study. J Clin Pathol. 2014;67(1):33-9.

18. Gasparini P, Casanova M, Villa R, Collini P, Alaggio R, Zin A, et al. Anaplastic lymphoma kinase aberrations correlate with metastatic features in pediatric rhabdomyosarcoma. Oncotarget. 2016;7(37): 58903-14.

19. Corao DA, Biegel JA, Coffin CM, Barr FG, Wainwright LM, Ernst LM, et al. ALK expression in rhabdomyosarcomas: correlation with histologic subtype and fusion status. Pediatr Dev Pathol. 2009;12(4):275-83

20. Cao L, Yu Y, Bilke S, Walker RL, Mayeenuddin LH, Azorsa DO, et al. Genome-wide identification of PAX3-FKHR binding sites in rhabdomyosarcoma reveals candidate target genes important for development and cancer. Cancer Res. 2010;70(16):6497-508.

21. Ishibashi Y, Miyoshi H, Hiraoka K, Arakawa F, Haraguchi T, Nakashima S, et al. Anaplastic lymphoma kinase protein expression, genetic abnormalities, and phosphorylation in soft tissue tumors: Phosphorylation is associated with recurrent metastasis. Oncol Rep. 2015;33(4):1667-74.

22. Peron M, Lovisa F, Poli E, Basso G, Bonvini P. Understanding the interplay between expression, mutation and activity of ALK receptor in rhabdomyosarcoma cells for clinical application of smallmolecule inhibitors. PLoS One. 2015;10(7):e0132330.

23. Fleuren EDG, Vlenterie M, van der Graaf W, Hillebrandt-Roeffen MHS, Blackburn J, Ma X, et al. Phosphoproteomic profiling reveals ALK and MET as novel actionable targets across synovial sarcoma subtypes. Cancer Res. 2017;77(16):4279-92.

24. Megiorni F, McDowell HP, Camero S, Mannarino O, Ceccarelli S, Paiano M, et al. Crizotinib-induced antitumour activity in human alveolar rhabdomyosarcoma cells is not solely dependent on ALK and MET inhibition. J Exp Clin Cancer Res. 2015;34:112.

25. Nishimura R, Takita J, Sato-Otsubo A, Kato M, Koh K, Hanada R, et al. Characterization of genetic lesions in rhabdomyosarcoma using a high-density single nucleotide polymorphism array. Cancer Sci. 2013;104(7):856-64.

26. van Gaal JC, Roeffen MH, Flucke UE, van der Laak JA, van der Heijden G, de Bont ES, et al. Simultaneous targeting of insulin-like growth factor-1 receptor and anaplastic lymphoma kinase in embryonal and alveolar rhabdomyosarcoma: a rational choice. Eur $\mathrm{J}$ Cancer. 2013;49(16):3462-70.

27. Shaw AT, Kim DW, Mehra R, Tan DS, Felip E, Chow LQ, et al. Ceritinib in ALK-rearranged non-small-cell lung cancer. N Engl J Med. 2014;370(13):1189-97.

28. Friboulet L, Li N, Katayama R, Lee CC, Gainor JF, Crystal AS, et al. The ALK inhibitor ceritinib overcomes crizotinib resistance in non-small cell lung cancer. Cancer Discov. 2014;4(6):662-73.

29. Fleuren ED, Hillebrandt-Roeffen MH, Flucke UE, Te Loo DM, Boerman OC, van der Graaf WT, et al. The role of AXL and the in vitro activity of the receptor tyrosine kinase inhibitor BGB324 in Ewing sarcoma. Oncotarget. 2014;5(24):12753-68.

30. Vlenterie M, Hillebrandt-Roeffen MH, Schaars EW, Flucke UE, Fleuren ED, Navis AC et al. Targeting cyclin-dependent kinases in synovial sarcoma: palbociclib as a potential treatment for synovial sarcoma patients. Ann Surg Oncol. 2016;23(9):2745-52.

31. Chou TC. Theoretical basis, experimental design, and computerized simulation of synergism and antagonism in drug combination studies. Pharmacol Rev. 2006;58(3):621-81.

32. Zhang N, Fu JN, Chou TC. Synergistic combination of microtubule targeting anticancer fludelone with cytoprotective panaxytriol derived from panax ginseng against MX-1 cells in vitro: experimental design and data analysis using the combination index method. Am J Cancer Res. 2016;6(1):97-104.

33. Marsilje TH, Pei W, Chen B, Lu W, Uno T, Jin Y, et al. Synthesis, structure-activity relationships, and in vivo efficacy of the novel potent and selective anaplastic lymphoma kinase (ALK) inhibitor 5-chloro-N2-(2-isopropoxy-5-methyl-4-(piperidin-4-yl)phenyl)N4-(2-(isopropylsulf onyl)phenyl)pyrimidine-2,4-diamine (LDK378) currently in phase 1 and phase 2 clinical trials. J Med Chem. 2013;56(14):5675-90.

34. Hartmann B. p70S6 kinase phosphorylation for pharmacodynamic monitoring. Clin Chim Acta. 2012;413(17-18):1387-90.

35. Roux PP, Shahbazian D, Vu H, Holz MK, Cohen MS, Taunton J, et al. RAS/ERK signaling promotes site-specific ribosomal protein S6 phosphorylation via RSK and stimulates cap-dependent translation. J Biol Chem. 2007;282(19):14056-64.

36. Flatt PM, Pietenpol JA. Mechanisms of cell-cycle checkpoints: at the crossroads of carcinogenesis and drug discovery. Drug Metab Rev. 2000;32(3-4):283-305.

37. Chipuk JE, Green DR. Dissecting p53-dependent apoptosis. Cell Death Differ. 2006;13(6):994-1002.

38. Vakifahmetoglu H, Olsson M, Zhivotovsky B. Death through a tragedy: mitotic catastrophe. Cell Death Differ. 2008;15(7):1153-62.

39. Soldani C, Scovassi AI. Poly(ADP-ribose) polymerase-1 cleavage during apoptosis: an update. Apoptosis. 2002;7(4):321-8.

40. Sirvent A, Urbach S, Roche S. Contribution of phosphoproteomics in understanding SRC signaling in normal and tumor cells. Proteomics. 2015;15(2-3):232-44.

41. Yeatman TJ. A renaissance for SRC. Nat Rev Cancer. 2004;4(6) 470-80.

42. Chen Q, Zhou Z, Shan L, Zeng H, Hua Y, Cai Z. The importance of Src signaling in sarcoma. Oncol Lett. 2015;10(1):17-22.

43. Wan X, Yeung C, Heske C, Mendoza A, Helman LJ. IGF-1R Inhibition Activates a YES/SFK bypass resistance pathway: rational basis for co-targeting IGF-1R and Yes/SFK kinase in rhabdomyosarcoma. Neoplasia. 2015;17(4):358-66.

44. Pappo AS, Vassal G, Crowley JJ, Bolejack V, Hogendoorn PC, Chugh R, et al. A phase 2 trial of R1507, a monoclonal antibody to the insulin-like growth factor-1 receptor (IGF-1R), in patients with recurrent or refractory rhabdomyosarcoma, osteosarcoma, synovial sarcoma, and other soft tissue sarcomas: results of a sarcoma alliance for research through collaboration study. Cancer. 2014;120(16):2448-56.

45. Weigel B, Malempati S, Reid JM, Voss SD, Cho SY, Chen HX, et al. Phase 2 trial of cixutumumab in children, adolescents, and young adults with refractory solid tumors: a report from the Children's oncology group. Pediatr Blood Cancer. 2014;61(3): $452-6$. 